\title{
Photo-emission electron microscopy (PEEM) heating investigations of a natural amphibole sample
}

\author{
J.-A. WARTHO* \\ Department of Earth Sciences, University of Leeds, Leeds, LS2 9JT, UK
}

\begin{abstract}
PEEM allows 'real-time' observations to be made of solid-state transformations and other high-temperature processes taking place during vacuum-heating up to $c .2000^{\circ} \mathrm{C}$. The solid state transformations of an amphibole-rich hornblendite specimen have been observed in the temperature range of $750-1000^{\circ} \mathrm{C}( \pm$ $50^{\circ} \mathrm{C}$ ). Between $c .970-990^{\circ} \mathrm{C}$ a rapid change in orientation contrast was observed, indicating a structural rearrangement from an oxyhomblende crystal lattice to a clinopyroxene structure. This phase retains the original amphibole shape and texture (including two $120^{\circ}$ intersecting cleavage traces), but possesses a clinopyroxene crystal structure. At higher temperatures this phase is seen to decompose, forming iron oxides and other fine-grained products. PEEM has provided useful information on both the nature and rates of transformation of natural amphiboles which has proved invaluable in our understanding of the mineralogically-controlled mechanisms of argon release during ${ }^{40} \mathrm{Ar} /{ }^{39} \mathrm{Ar}$ dating of amphibole samples.
\end{abstract}

KEYworDs: Photo-emission electron microscopy, vacuum-heating, amphiboles, solid state transformations.

\section{Introduction}

THE photo-emission electron microscope (PEEM) was designed by L. Wegmann and then commercially developed in 1968 by Balzers (Liechtenstein) to allow metallurgists to make 'real-time' observations of solid-state transformations taking place during vacuum-heating up to $c .1000^{\circ} \mathrm{C}$. For this metallurgical application, the microscope obtains images by using ultra-violet light to stimulate electron emission from the surface of the metal. Reviews of the microscope and its applications may be found in Schweizer and Form (1970) and Wegmann (1972). Details of the University of Leeds Balzers Metioscope KE3 can be found in Burnett (1980) and Hammond et al. (1987).

In this study, two experiments have been carried out on an amphibole-bearing hornblendite sample, vacuum-heated up to $c .1000^{\circ} \mathrm{C}$. To the best of the

\footnotetext{
* Present address: Department of Earth Sciences, Open University, Walton Hall, Milton Keynes, MK7 6AA. UK
}

author's knowledge, these are the first in-situ observations made using the PEEM vacuum-heating technique on a geological specimen. Previous PEEM studies focused on alkali feldspars (Laves, 1974a), plagioclases (Weber, 1972, and Laves, 1974b), a basalt sample (Blaschke, 1970), and a cassiterite sample (Wegmann, 1972), but these studies were carried out at either room temperature or a fixed temperature of $400^{\circ} \mathrm{C}$. This microscope offers the opportunity of observing solid-state transformations taking place during the vacuum-heating of geological specimens. It also offers the opportunity of gaining information on the rates of transformation reactions. In addition, the Leeds instrument offers a hightemperature straining stage which has been used to observe deformation behaviour in titanium and aluminium alloys (Hammond et al., 1987). These amphibole PEEM experiments were carried out as part of a study to try to understand how structural transformations and chemical changes may influence the rate of argon release during routine ${ }^{40} \mathrm{Ar} /{ }^{39} \mathrm{Ar}$ dating of amphibole samples. 


\section{Experimental methods and description of the PEEM}

A coarse-grained hornblendite, $\mathrm{K} 507$, from the Kamila Amphibolite Belt, Kohistan island arc system, Northern Pakistan, was used for this study. The sample is composed of c. $99 \%$ tschermakitic hornblende $\left(\left(\mathrm{Na}_{0.6} \mathrm{~K}_{0.1}\right) \mathrm{Ca}_{1.8}\left(\mathrm{Fe}_{1.9} \mathrm{Mg}_{2.4} \mathrm{Ti}_{0.2}\right)\right.$ $\left.\mathrm{Si}_{6.4} \mathrm{Al}_{2.4} \mathrm{O}_{22}(\mathrm{OH})_{2}\right)$ with minor inclusions of rutile, ilmenite, titano-magnetite, epidote, quartz and apatite, with trace chlorite and sphene found infilling fractures and grain boundaries (Wartho, 1991). Several $6 \times 4 \mathrm{~mm}$ hand-ground cylinders of this rock sample were prepared.

The first pilot hornblendite cylinder (PEEM 1) was inserted into a stainless steel specimen holder and held in place by three grub screws. The specimen surface was ground down to $4.5 \mu \mathrm{m}$ using sanding papers (wet and dry technique) so that the specimen and holder surfaces were level. These surfaces were polished to $1 \mu \mathrm{m}$ on diamond laps and finished off on a rotating ferrous cloth with a slurry mixture of 0.05 $\mu \mathrm{m}$ aluminium oxide and ethanol.

A different method was employed for the second experiment (PEEM 2) which produced better results. A titanium holder was used as it is more resistant to the higher temperatures $\left(>1000^{\circ} \mathrm{C}\right)$ encountered during heating. The holder was ground down on sanding papers and polished using a slurry of $3 \mu \mathrm{m}$ aluminium oxide in $0.5 \%$ hydrofluoric acid and $0.5 \%$ nitric acid mixture on a cloth lap and finished off with a slurry of $0.05 \mu \mathrm{m}$ aluminium oxide. The hornblendite core was prepared separately. The cylinder was set in resin (10 $\mathrm{cm}^{3}$ Metset resin (30-60\% styrene) plus five drops of hardener (methyl ethyl ketone peroxide)). The resin surface was ground down to reveal the core surface and polished on silk laps using diamond pastes (respectively $9,3,1,0.25 \mu \mathrm{m}$ ). A final high quality finish was obtained using the chemical-mechanical Syton polishing technique, described by Lloyd (1987).

The resin was dissolved in acetone leaving behind the polished hornblendite core. Several cores were prepared in this manner. One core was selected which fitted flush in the titanium specimen holder, and was held in place by three grub screws. The polished core sample and specimen holder were carbon coated, inserted into an annular furnace (see Fig. 3, Hammond et al., 1987) and placed upside down within the microscope. The instrument was pumped down to obtain a vacuum of $1 \times 10^{-6}$ torr. A maximum temperature of $1000^{\circ} \mathrm{C}$ is achievable using the annular furnace setup. Higher temperatures can be obtained using flat sheet specimens heated by an electron beam.

The distinct characteristic of this microscope is that the specimen itself is the source of electrons. The work function for electron emission from the surface of the specimen is overcome by irradiating the surface with high energy photons in the ultra-violet range (280 $\mathrm{nm}$ wavelength). Four high-pressure mercury vapour arc lamps are focused through quartz lenses onto a highly polished plate from where the ultra-violet light is reflected onto the specimen surface because there is insufficient space to focus the lamps directly onto the specimen (Fig. 1). The plate also acts as an anode, which is grounded while the specimen is connected to a negative high voltage supply. The specimen/anode gap is held at a positive potential difference of $30-40 \mathrm{kV}$. This helps accelerate the photo-electrons emitted from the specimen surface. However, during the first experiment, the potential was lowered to $14 \mathrm{kV}$ due to high vapour loss from the hornblendite accompanied by arcing problems. This explains the poor quality of the images obtained during this first experiment. In the second experiment the potential was held at $30 \mathrm{kV}$.

A tungsten-wire-wound furnace heats the body of the specimen holder, therefore, the viewed surface of the material is heated by conduction through the grub screws into the body of the specimen. The temperature is monitored by a $\mathrm{Pt}-10 \% \mathrm{Rh}$ thermocouple running inside the specimen holder touching the base of the sample. Average heating rates of $1.7^{\circ} \mathrm{C} / \mathrm{min}$ and $1.3^{\circ} \mathrm{C} / \mathrm{min}$ respectively were used in the two experiments. A slow heating rate is essential as a large thermal gradient can develop along the length of the specimen, often with variations of $200-300^{\circ} \mathrm{C}$. In some cases, the body of the specimen and sometimes the holder itself can melt before the surface reaches the desired temperature. In the first experiment (PEEM 1), the base of the stainless steel holder melted, breaking the thermocouple connection, thus terminating the experiment. For this reason a titanium holder was used in the second experiment which is more resistant to high temperatures (i.e. $1000^{\circ} \mathrm{C}$ ).

The first sample was outgassed at $750^{\circ} \mathrm{C}$ for approximately $2 \mathrm{~h}$, and in the second experiment the sample was outgassed at $750^{\circ} \mathrm{C}$ for $5 \mathrm{~h}$ and then $c$. $830^{\circ} \mathrm{C}$ for a further $5 \mathrm{~h}$. the sample PEEM 2 was preheated for a longer period and higher temperatures to help outgas the sample. It is known from previous heating experiments that a large quantity of hydrogen is released at $750-800^{\circ} \mathrm{C}$ during the early stages of transformation from hornblende to oxyhornblende (Barnes, 1930; Phillips et al., 1988a, 1989; and Wartho et al., 1991).

Electrons emitted from the surface of the specimen pass through an aperture in the anode plate and are focused by an electromagnetic objective lens, situated immediately below the anode. The remainder of the lens system consists of two further electromagnetic magnifying lenses, the intermediate and projector lenses (Fig. 1). The image is received 


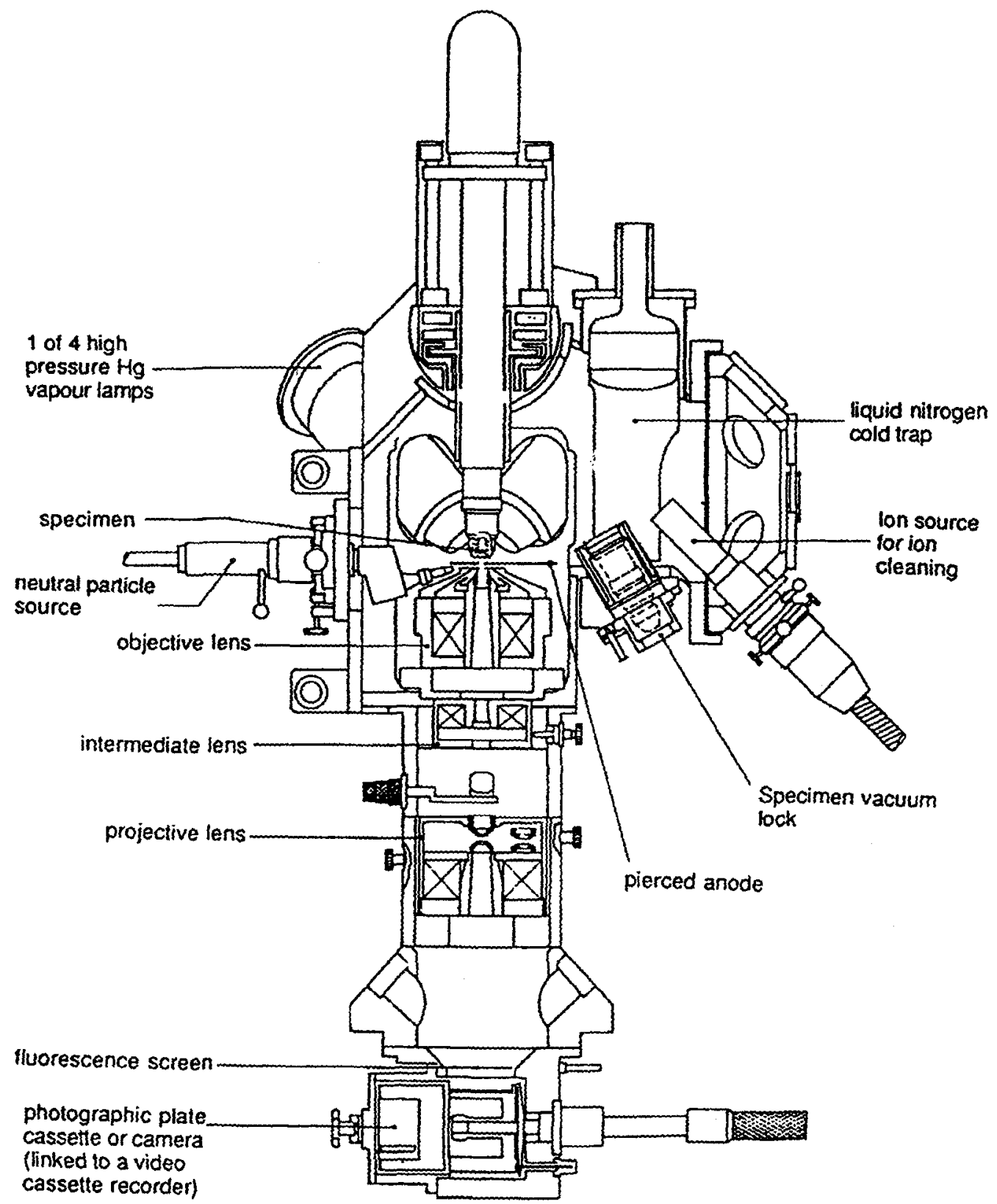

Fig. 1. Cross-section of the photo-emission electron microscope (from Wegmann, 1972).

on a fluorescent screen or on a photographic film emulsion in a five plate cassette (Bumett, 1980). During the two experiments the image was recorded via a cameta onto a video cassette. The use of a video camera leads to some reduced resolution and contrast. However, it is a very effective way of observing any contrast changes during heating. It was not possible to use photographic plates in the second experiment; due to technical difficulties the fluorescent screen could not be lowered. 
The contrast in the image results solely from variations in the electron emission across the surface of the sample. These variations are determined by three factors: (1) crystallographic orientation, giving orientation contrast between grains; (2) material or composition, effectively giving atomic number contrast between grains; and (3) surface topography effects (Wegmann, 1972; Hammond et al., 1987).

In general, all these types of contrast appear simultaneously in the image. This overlapping of different types of contrast is in most cases unwanted. The relief contrast can be avoided by examining highly polished surfaces, and this explains the better quality of images obtained in the PEEM 2 experiment, where the sample was Syton polished. Examples of the different types of contrast observed in specimens can be found in Wegmann (1972).

The resolution of the microscope is determined by the work function, electron optics and the depth from which the photo-electrons are emitted. This in turn is dependent on the type of material being used, but for metals the resolution is $c$. $5-20 \mathrm{~nm}$. For semiconductors or insulators, the depth of information does not seem to exceed $50 \mathrm{~nm}$ (Wegmann, 1972).

After the first experiment (PEEM 1) the hornblendite sample was forcibly removed from the melted specimen holder and the pieces were mounted in an epoxy resin block, ground down and polished. The fragments were then viewed using backscattered electron (BSE) mode on the scanning electron microscope (SEM). The second experiment (PEEM 2) employing the titanium holder was heated to a top temperature of approximately $1000^{\circ} \mathrm{C}$. The extracted amphibole specimen and holder were carbon coated and viewed in BSE and pseudo-channelling modes.

\section{Results}

The solid-state transformations of the two hornblendite specimens (K507) were viewed using the PEEM during in vacuo heating, between $750^{\circ} \mathrm{C}$ and $1020^{\circ} \mathrm{C}$. When comparing the recorded temperature measurements from the PEEM and the observed temperature of the reactions from vacuum-heated experiments (Wartho, 1991, and Wartho et al., 1991), it was found that the PEEM temperatures were c. $30^{\circ} \mathrm{C}$ lower. This is not surprising, considering the fact that heat is transferred along the specimen holder and into the sample via three grub screws which are located towards the top half of the cylindrical specimen. However, the thermocouple is located at the base of the specimen and is likely to record lower temperatures than at the viewing surface. Therefore, it is estimated that the quoted temperatures are probably only accurate to $\pm 50^{\circ} \mathrm{C}$.

Figures $2 a-e$ show the hornblendite sample surface during progressive heating. Fractures, cleavage traces and subgrain boundaries are visible in these fields of view. The angles between cleavage traces (seen in Fig. $2 b$ and $2 c$ ) were measured to be only $113^{\circ} / 67^{\circ}$, instead of $124^{\circ} / 56^{\circ}$ as expected for amphiboles. This is simply because the specimen surface is not perpendicular to the $z$-axis of the grains. Unfortunately, due to the heating of the specimen and holder, the field of observation becomes slightly displaced. It was decided not to readjust the position, as the image would have to have been refocused after each adjustment along with the brightness and contrast. It was felt that this would make interpretation of any subtle image changes difficult to decipher. Therefore, the refocusing, brightness and contrast controls were left unadjusted for extended periods of time until either, an uninteresting region was reached, when the specimen would be relocated, or, the image needed refocusing. The curved line in Fig. $2 a-c$ is the edge of the fluorescent screen.

\section{Discussion}

Figure $2 a$ shows a photomicrograph taken at $850^{\circ} \mathrm{C}$ showing distinct cleavage traces and sharp subgrain boundaries. Figure $2 b$ is a photomicrograph of the specimen surface at $920^{\circ} \mathrm{C}$ showing similar contrast to Figure $2 a$ (although the brightness and contrast were adjusted between the videotaping of these two images), however, the subgrain boundaries are less distinct and appear to be fuzzy. Comparing Fig. $2 b$ and $c$ taken at $920^{\circ} \mathrm{C}$ and $940^{\circ} \mathrm{C}$ respectively, the immediate difference between the two photomicrographs is the sudden contrast change observed in some of the subgrains. These two photomicrographs were taken from the video screen using Polaroid film at the same exposure settings. Screen brightness and contrast were not adjusted during either the heating period, or during the taking of the photomicrographs. At $940^{\circ} \mathrm{C}$ some of the subgrains have become noticeably lighter or darker (especially the dark regions in the bottom right hand corner of the photomicrograph and in the central bright portion) (Fig. 2c). The subgrain boundaries have once again become much more distinct at $940^{\circ} \mathrm{C}$. There appears to be no detectable subgrain boundary movement in the PEEM 2 experiment due to possible boundary migration or recrystallization. In the first experiment (PEEM 1) a 'front' was observed moving through a large amphibole grain between approximately $970-990^{\circ} \mathrm{C}$ (Wartho et al., 1991). The brightness change observed in the PEEM 2 specimen indicates either a change in the composition or orientation.

From vacuum-heating studies on similar amphibole samples it is known that no large compositional variations occur over this temperature range, however, between 960 and $1030^{\circ} \mathrm{C}\left( \pm 25^{\circ} \mathrm{C}\right)$ a structural change has been observed from oxyhorn- 

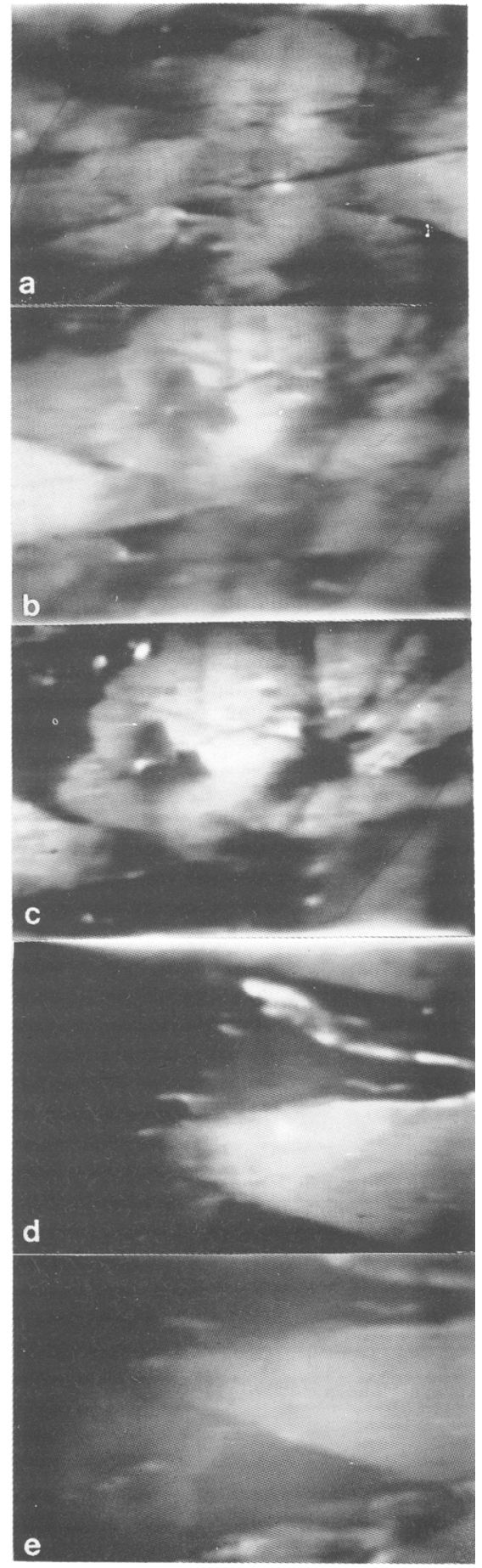

Scale $=1 \mathrm{~mm}$ blende to a suspected clinopyroxene arrangement (Wartho et al., 1991). Follow-up transmission electron microscope (TEM) selected area diffraction (SAED) patterns confirm an $8.8 \AA d$-spacing value which is indicative of the $b$ cell dimension (010) of a clinopyroxene structure. No significant differences in chemical composition were found in the electron microprobe analyses of the oxyhornblende and the clinopyroxene (Wartho, 1991). This suggests that the observed contrast changes from Fig. $2 b$ to $c$ are due to orientation contrast rather than a compositional alteration. Schweizer and Form (1970) observed a weakening of the orientation contrast during a rapid recrystallisation event in a slowly heated copper sample, however, they were unable to explain the reasons for the contrast change. This may explain the fuzzy subgrain boundaries in Figure $2 \mathrm{~b}$. Although no recrystallization process is taking place in the hornblendite sample, a rapid structural rearrangement of the crystal structure during a change from oxyhornblende to clinopyroxene is occurring, which may account for the nature of the diffuse subgrain boundaries.

This new phase appears to be a transition phase between a clinopyroxene and an amphibole and has been tentatively classified a 'pyribole' by Lee $e t a l$. (1991) after the term used by Johannsen (1911) where the term "pyribole is suggested as a substitute for the awkward words pyroxene and/or amphibole" (Johannsen, 1911). Thompson $(1970,1978)$ uses the term pyribole with reference to amphiboles that "may be regarded in the sense of 'mineralogical mules' derived from a mating of distinct species, in this case mica and pyroxene" (Thompson, 1978). Therefore, viewing the definitions of 'pyribole' it would seem inappropriate to use this term to characterize the hybrid oxyhornblende-pyroxene phase, and instead another term is used, 'amphiboloid' (i.e. having the form or appearance of an amphibole), which will be adopted here. The new amphiboloid phase can be termed a pseudomorph, as it retains the original hornblende shape and texture, including the two $120^{\circ}$ intersecting cleavages.

The use of the PEEM to make in-situ observations during the vacuum-heating of this amphibole sample have demonstrated the fast nature of the transformation from oxyhornblende to the amphiboloid phase. This transformation occurred over a very narrow temperature range of $c .20^{\circ} \mathrm{C}$. It was previously thought that the oxyhornblende-amphiboloid reaction took place more slowly over a $50^{\circ} \mathrm{C}$ temperature range.

Fig. 2. Photomicrographs of the PEEM 2 hornblendite sample at different temperatures $\left( \pm 50^{\circ} \mathrm{C}\right) .($ a $) 850^{\circ} \mathrm{C}$, (b) $920^{\circ} \mathrm{C},(c) 940^{\circ} \mathrm{C},(d) 970^{\circ} \mathrm{C}$, and $(e) 990^{\circ} \mathrm{C}$. 
The photomicrographs taken at $970^{\circ} \mathrm{C}$ and $990^{\circ} \mathrm{C}$ (Fig. $2 d$ and $e$ respectively) show the development of a new bright phase along subgrain boundaries and cross-cutting some subgrains. These bright phases have been identified as iron oxides (consisting of titano-magnetite) and are seen developing along hornblende cleavage traces, grain boundaries and fractures. Phillips et al. (1988b) state that at $c$. $1000^{\circ} \mathrm{C}$ oxidation of the ferrous ions due to the dehydrogenation reaction; $\mathrm{Fe}^{2+}+\mathrm{OH}^{-}=\mathrm{Fe}^{3+}+\mathrm{O}^{2-}$ $+1 / 2 \mathrm{H}_{2}$ (Barnes, 1930), has proceeded to such an extent that the compensation mechanisms necessary to maintain structural stability (or metastability) are unable to cope and the structure decomposes, thus forming iron oxides. SEM examination of the extracted PEEM 2 sample and holder revealed the presence of small quantities of other fine-grained reaction products, namely clinopyroxene and plagioclase.

\section{Conclusions}

From the in-situ PEEM heating experiments, an orientation contrast change was observed at approximately $920-940^{\circ} \mathrm{C}\left( \pm 50^{\circ} \mathrm{C}\right)$ with the alteration of the oxyhornblende crystal structure to a hybrid amphiboloid phase (Fig. $2 b$ and $c$ ). A $970-990^{\circ} \mathrm{C}$ temperature bracket has been defined for this transformation, constrained by the presence of oxyhornblende at $960^{\circ} \mathrm{C} \pm 25^{\circ} \mathrm{C}$ (from powder camera X-ray diffraction data (Wartho et al., 1991)) and Phillips et al. (1988b) observations on the breakdown of the oxyhornblende structure at $c$. $1000^{\circ} \mathrm{C}$ and the formation of iron oxides.

This instrument has allowed valuable insights to be made into both the character and rates of transformation of natural amphibole samples, and the effects this has on argon release during the ${ }^{40} \mathrm{Ar} /{ }^{39} \mathrm{Ar}$ step-heated dating technique. A simple volume diffusion model is not suitable for determining the thermal history of a hornblende sample because the mechanisms of argon release during vacuum-heating are different from those operating during metamorphism. However, the role of fractures and defects in the breakdown reactions may provide an indirect link to argon gradients in amphibole samples.

In summary, the following reactions were observed during the vacuum-heating of an amphibole sample in the PEEM: (1) oxyhornblende = amphiboloid (clinopyroxene-structured phase) (c. $970-990^{\circ} \mathrm{C}$ ); and (2) amphiboloid = fine-grained iron oxides $\left(c .1000^{\circ} \mathrm{C}\right)$, plus fine-grained clinopyroxene and plagioclase.

\section{Acknowledgements}

I would like to thank Tony Nichells for patiently operating the PEEM during these experiments in the Department of Electron Optics at Leeds University, Keith Wayne for polishing the titanium holder, Phil Fields for constructing the titanium holder to take the necessary grub screws, Rob Knipe for taking SAED pattern photomicrographs of the amphiboloid phase, and Eric Condliffe for coming up with the term 'amphiboloid'. I also thank Wayne Dollase and Matt Hacker for useful comments on the draft copy of this manuscript. Jo Wartho acknowledges a NERC research studentship, undertaken at Leeds University.

\section{References}

Barnes, V.E. (1930) Changes in hornblende at about $800^{\circ} \mathrm{C}$. Amer. Mineral., 15, 393-417.

Blaschke, R. (1970) Spezifische Oberflachen und Grenzflachen der Mineralphasen als Gelfugeparameter. Fortschr. Mineral., 47, 197-241.

Burnett, B. (1980) Application of the photo-emission electron microscope to the study of reactions in steels. Ph.D. thesis (unpubl.) Univ. Leeds, UK.

Hammond, C., Nichells, A. and Patton, N.E. (1987) Photoemission Electron Microscopy of superplastic deformation processes. Metallography, 20, 199-212.

Johannsen, A. (1911) Petrographic terms for field use. $J$. Geol., 19, 317-22.

Laves, F. (1974a) On the use of Photo-Emission Electron Microscopy (PEEM) on decomposition features in minerals and other materials. Amer. Mineral., 59, 1136-7.

Laves, F. (1974b) Domain and deformation textures in plagioclases and their investigation by photoemission-electron-microscopy (PEEM) and by transmission electron microscopy. In The feldspars, (Mackenzie, W.S. and Zussman, J., eds.). Manchester University Press, United Kingdom, 536-50.

Lee, J.K.W., Onstott, T.C., Cashman, K.V., Cumbest, R.J. and Johnson, D. (1991) A critical evaluation of the ${ }^{40} \mathrm{Ar} /{ }^{39} \mathrm{Ar}$ incremental heating of hornblende. Geology, 19, 872-6..

Lloyd, G.E. (1987) Atomic number and crystallographic contrast images using SEM: a review of backscattered electron techniques. Mineral. Mag., 51, 3-19.

Phillips, M.W., Popp, R.K. and Clowe, C.A. (1988a) Structural adjustments accompanying oxidationdehydrogenation in amphiboles. Amer. Mineral., 73, 500-6.

Phillips, M.W., Popp, R.K., Clowe, C.A. and Pinkerton, A.A. (1988b) Oxidation-induced 'exsolution' of iron oxide in grunerite. Eos, 69, 523.

Phillips, M.W., Draheim, J.E., Popp, R.K., Clowe, C.A. 
and Pinkerton, A.A. (1989) Effects of oxidationdehydrogenation in tschermakitic hornblende. Amer. Mineral., 74, 764-73.

Schweizer, M. and Form, G.W. (1970) PEEM: A new instrument for metallographic studies. Metals and Materials, 4, 369-73.

Thompson, J.B. (1970) Geometrical possibilities for amphibole structures: Model Biopyriboles. Amer. Mineral., 55, 292-3.

Thompson, J.B. (1978) Biopyriboles and polysomatic series. Amer. Mineral., 63, 239-49.

Wartho, J-A. (1991) Argon isotope systematics and mineralogy of metamorphic hornblendes from the Karakoram. Ph.D. thesis (unpubl.), Univ. Leeds, UK.

Wartho, J-A., Dodson, M.H., Rex, D.C. and Guise, P.G. (1991) Mechanisms of argon release from Himalayan metamorphic hornblendes. Amer. Mineral., 76,
1446-8.

Weber, L. (1972) Das Entmischungsverhalten der Peristerite; Untersuchungen zur chemischen Charakterisierung mittels Photoemissions-Elektronenmikroskop und SekundRrionen-Mikroanalysator (The unmixing behaviour of peristerite; investigation for chemical characterisation using the Photoemission-Electron-Microscope and an ionmicroanalyser). Schweiz. Mineral. Petrog. Mitteil., 52, 349-72.

Wegmann, L. (1972) The photo-emission electron microscope: its technique and applications. $J$. Microscopy, 96, 1-23.

[Manuscript received 27 January 1994:

revised 25 February 1994] 